\title{
Development Using Simulation on a 4-DOF Passive Suspension System with Thorax-Pelvis
}

\author{
A.V. Bankar, N.S.Deshpande, N.V.Patil, R.Ramya, V.R.Varude, A.C.Mitra \\ (Department of Mechanical Engineering, M.E.S.College of Engineering, S.P. Pune University, India)
}

\begin{abstract}
One of the most intriguing tasks for modern day car designers is to meet the latest standards and norms for optimum ride comfort and road holding prevailing across the globe. The parameters influencing the performance are closely related with each other, such that this complex multi-variable optimization is difficult to achieve. The present work aims at analyzing and comparing the linear and non-linear characteristics of a spring under a wide range of operating conditions. A Multi-DOF quarter car model has been proposed to study the cause-effect relationship using MATLAB SIMULINK. A case study on the effect of Non-Linear variation of spring stiffness has been presented. Simplifications made in the dynamic analysis such as linearity of spring's stiffness have resulted in inaccurate representation of the physical model and have substantial deviations from the real-world conditions. The results thus obtained from non-linear behavior of spring seem to be in close agreement with the experimental results tested in real time environment.
\end{abstract}

Keywords:4-DOF,Head displacement,Matlab-SIMULINK, Non-Linear Springs, Ride Comfort, Road Holding, Vehicle Dynamics.

\section{INTRODUCTION}

Suspension system plays a major role in vehicle design. Finer design of passive suspension system is necessary to improve the vehicle quality. There are two main objectives of passive suspension system, one is to isolate the external disturbance by road irregularities on the car body from passengers to enhance ride comfort and other is to keep firm contact between the tyres and the road to provide good road holding[8]. However, both of these aims for conflicting requirements. To provide good road holding stiff suspension system is required whereas on the other side, to improve ride comfort a soft suspension system is needed [5].Thus, an optimised solution for ride comfort and road holding should be attained and incorporated for maximum efficiency in automobiles.So far, in designing of passive suspension system spring is considered to be linear. But, this is not true in real time conditions springs behave are non-linearly, due to interleaf friction in leaf spring or due to friction in bushings and struts [4]. Thus instead of linear graph between force and displacement, it exhibits a polynomial behaviour. In the same way, due to change in chemical and physical properties of damper parts, graph between velocity and damping force is also non-liner and it also exhibits polynomial behaviour.Nonlinearity in damper has minor effect on suspension system as compared to spring, hence it is considered constant [3]. Emphasis is on spring effect of non-linearity in passive suspension system. Spring nonlinearity is due to two reasons-one is its material properties and its geometry as both possess non-linear behaviour [4]. In this paper, a proposed mathematical model is run on Simulink to understand the behaviour of spring along with, its effect on ride comfort, road holding and, displacement of head. Thus, to understand the effect of non-linearity in spring, both linear and non-linear behaviour of springs are compared.

\section{MATHEMATICAL MODEL}

Fig.1 illustrates a four degree of freedom quarter car model. Objective of the study is to optimise the ride comfort and road holding along with minimum displacement of head [1]. The parameters of Hyundai Elantra 1992 model are considered for analysis of both linear and non-linear passive vehicle suspension model [6]. $M_{s}$ and $M_{u}$ are sprung and unsprung masses respectively. These together combine a total of one-fourth of the total vehicle mass. Damping and stiffness co-efficient for the suspension are $C_{s}$ and $K_{s}$. $K_{c}$ and $C_{c}$, are cushion elastic properties being spring and a dashpot. Driver's body is divided into two main frames, the upper body (head) and lower body. This is a 2-DOF system connected with spring and a dashpot combination of $K_{p}$ and $C_{p}$ respectively.The movement of system is restricted to vertical direction only, as the excitation is due to speed bump. The displacements of sprung and unsprung masses at any given point of time are given by $Z_{s}$ and $Z_{u}$ for a step input of $q \cdot Z_{b}$ and $Z_{h}$ are the vertical displacements of lower body and head. The above-mentioned values are measured from there static equilibrium positions to neglect the effect of gravity while deriving the equations. Note that $\dot{Z}$ is the velocity and $\ddot{Z}$ is the acceleration of respective parameters 


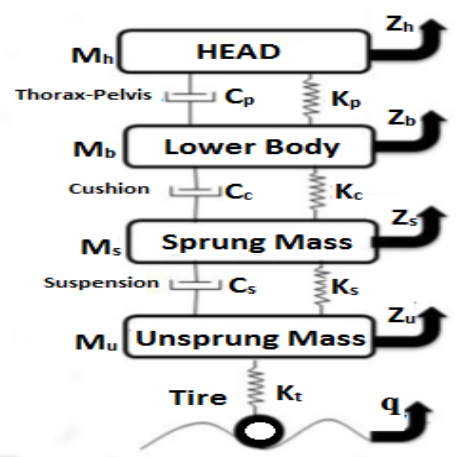

Fig.1 4-DOF quarter car model.

Table-1 Parameters for analysis of linear and non-linear model.

\begin{tabular}{|c|l|c|c|l|c|}
\hline$M_{h}$ & $\begin{array}{l}\text { Mass of upper body } \\
\text { and head }\end{array}$ & $20 \mathrm{Kg}$ & $M_{s}$ & Sprung mass & $240 \mathrm{Kg}$ \\
\hline$M_{b}$ & $\begin{array}{l}\text { Mass of lower body } \\
\text { and seat }\end{array}$ & $45 \mathrm{~kg}$ & $M_{u}$ & Unsprung mass & $36 \mathrm{Kg}$ \\
\hline$C_{p}$ & $\begin{array}{l}\text { Damping coefficient } \\
\text { of thorax and pelvis }\end{array}$ & $\begin{array}{c}1360 \\
\mathrm{Ns} / \mathrm{m}\end{array}$ & $C_{c}$ & $\begin{array}{l}\text { Damping } \\
\text { coefficient of seat } \\
\text { cushion }\end{array}$ & $\begin{array}{c}1649.03 \\
\mathrm{Ns} / \mathrm{m}\end{array}$ \\
\hline$K_{p}$ & $\begin{array}{l}\text { Spring stiffness of } \\
\text { thorax and pelvis }\end{array}$ & $\begin{array}{c}45005.3 \\
\mathrm{~N} / \mathrm{m}\end{array}$ & $K_{c}$ & $\begin{array}{l}\text { Spring stiffness of } \\
\text { seat cushion }\end{array}$ & $20000 \mathrm{~N} / \mathrm{m}$ \\
\hline$C_{s}$ & $\begin{array}{l}\text { Damping coefficient } \\
\text { of suspension }\end{array}$ & $\begin{array}{c}1385.4 \\
\mathrm{Ns} / \mathrm{m}\end{array}$ & $K_{t}$ & Stiffness of tyre & $\begin{array}{c}181818.88 \\
\mathrm{~N} / \mathrm{m}\end{array}$ \\
\hline$K_{s}$ & $\begin{array}{l}\text { Spring stiffness of } \\
\text { suspension }\end{array}$ & $\begin{array}{c}12394 \\
\mathrm{~N} / \mathrm{m}\end{array}$ & $\mathrm{Q}$ & Road profile & \begin{tabular}{c} 
Step Wave \\
\hline
\end{tabular}
\end{tabular}

\section{ROAD PROFILE}

Input signal used to describe the speed bump is step wave,using MATLAB-SIMULINK the Simulation is carried out on corresponding step waves with three different widths of $0.5 \mathrm{~m}, 1 \mathrm{~m}$, and $2 \mathrm{~m}$. Height of bump is $0.1 \mathrm{~m}$.

\section{SPRING LINEARITY}

A linear spring is one with the linear relationship between force and displacement, meaning the force and displacement are directly proportional to each other.

The equations derived from Free Body Diagram (FBD)as per the Newton's Second Law of motion for linear model are:

$$
\begin{aligned}
& M_{h} \ddot{Z}_{h}=-C_{p}\left(\dot{Z}_{h}-\dot{Z}_{b}\right)-K_{p}\left(Z_{h}-Z_{b}\right) \\
& M_{b} \ddot{Z}_{b}=C_{p}\left(\dot{Z}_{h}-\dot{Z}_{b}\right)+K_{p}\left(Z_{h}-Z_{b}\right)-C_{c}\left(\dot{Z}_{b}-\dot{Z}_{s}\right)-K_{c}\left(Z_{b}-Z_{s}\right) \ldots \ldots \ldots \\
& M_{s} \ddot{Z}_{s}=C_{c}\left(\dot{Z}_{b}-\dot{Z}_{s}\right)+K_{c}\left(Z_{b}-Z_{s}\right)-C_{s}\left(\dot{Z}_{s}-\dot{Z}_{u}\right)-K_{s}\left(Z_{s}-Z_{u}\right) \ldots \ldots \\
& M_{u} \ddot{Z}_{u}=C_{s}\left(\dot{Z}_{s}-\dot{Z}_{u}\right)+K_{s}\left(Z_{s}-Z_{u}\right)-K_{t}\left(Z_{u}-q\right) \ldots \ldots \ldots \ldots \ldots \ldots \ldots \ldots \ldots \ldots \ldots \ldots \ldots
\end{aligned}
$$

The above linear equations are obtained for a given road excitation(q). The mass of driver is taken as $\mathrm{M}=65 \mathrm{~kg}$, thus $\mathrm{s} M_{H}=\frac{(2 M)}{7}$ and $M_{B}=\frac{(5 M)}{7}[2]$.

\section{DEVELOPMENT OF SIMULATION}

The effects of input that is road bump with different parameters have been studied. It is acutely observed that when a vehicle runs over a certain road bump profile at a particular velocity, the suspension system plays a vital role in transmitting the forces from road to head through a series of spring and damper combined system in order to minimize the transmitting forces. The forces are transferred from vehicle to the passenger body to head. A certain limit is specified by ISO 2631-1 of induced vibrations on body for ride comfort. The exceed in these limits of the forces results in disturbance in human comfort and fatigue in spinal 
cord of human body, as well as improper road holding phenomenon. Road holding parameter is an essential factor in maintaining the control of the vehicle.In this paper, analysis of suspension system is carried out with effect of width of the bump on head displacement, ride comfort and road holding. Also, comparisonis carried between linear and non-linear parameters of the spring stiffness and effects of the same on above factors.

\section{LINEAR SIMULINK MODEL}

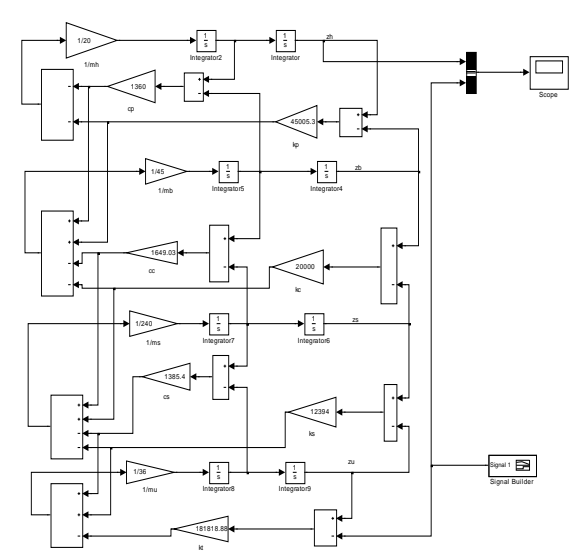

Fig.2 Linear SIMULINK model of quarter car model.

\section{LINEAR SIMULATION ANALYSIS}

$2 \mathrm{~m}, 1 \mathrm{~m}, 0.5 \mathrm{~m}$ width of bumps along with height of $0.1 \mathrm{~m}$ are considered for mathematical modelling and simulation. The results are graphical representation of ride comfort, road holding and, head displacement with respect to approach velocity of the vehicle $(0-40 \mathrm{Km} / \mathrm{h})$ corresponding to a constant suspension stiffness, $12,394 \mathrm{~N} / \mathrm{m}$ and damping coefficient $1385.4 \mathrm{~N}-\mathrm{s} / \mathrm{m}$.[7]Fig.3 shows displacement of head verses time domain for a $2 \mathrm{~m}$ bump width with a velocity of $40 \mathrm{kmph}$. A peak displacement of $0.104 \mathrm{~m}$ is observed on the graph.

Table-2 Stiffness values for non-linear spring

\begin{tabular}{|l|c|}
\hline$K_{0}$ & $-2316.4 \mathrm{~N} / \mathrm{m}$ \\
\hline$K_{1}$ & $12394 \mathrm{~N} / \mathrm{m}$ \\
\hline$K_{2}$ & $-73696 \mathrm{~N} / \mathrm{m}$ \\
\hline$K_{3}$ & $3170400 \mathrm{~N} / \mathrm{m}$ \\
\hline
\end{tabular}

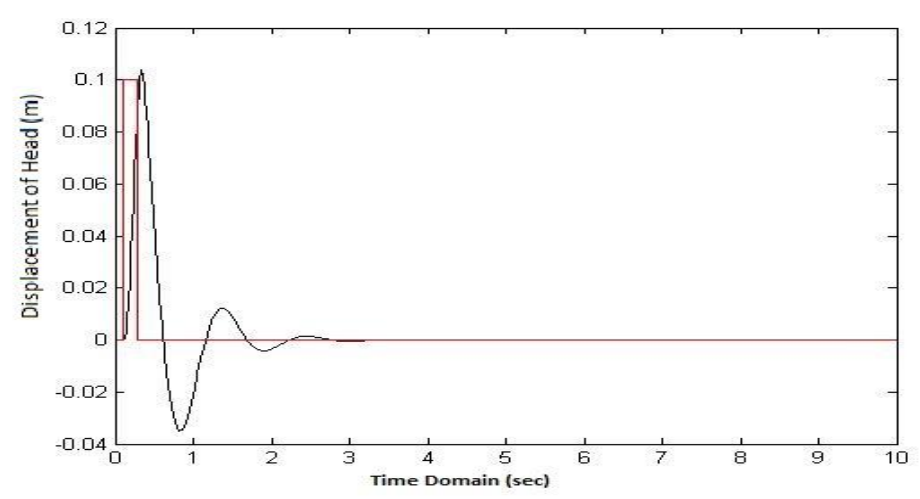

Fig.3 Linear Displacement of Head Vs Time Domain

VIII. SPRING NON-LINEARITY

The concept of spring non-linearity arises when the behaviour of the spring is not linear. In general, all the spring are non-linear to an extend as the displacement of the whole spring is not virtually equally distributed on application of force.The spring force $\left(\left(f_{s}\right)\right.$ is designed as Polynomial functionof third order as:[7]

$$
f_{s}=k_{0}+k_{1} \Delta x+k_{2} \Delta x^{2}+k_{3} \Delta x^{3}
$$


The non-linear spring parameters of Hyundai Elantra front suspension 1992 model are used[7].

.The equations derived from FBD by Newton's Second Law of motion for non-linear model are:

$M_{h} \ddot{Z}_{h}=-C_{p}\left(\dot{Z}_{h}-\dot{Z}_{b}\right)-K_{p}\left(Z_{h}-Z_{b}\right)$

$M_{b} \ddot{Z}_{b}=C_{p}\left(\dot{Z}_{h}-\dot{Z}_{b}\right)+K_{p}\left(Z_{h}-Z_{b}\right)-C_{c}\left(\dot{Z}_{b}-\dot{Z}_{s}\right)-K_{c}\left(Z_{b}-Z_{s}\right)$

$M_{s} \ddot{Z}_{s}=C_{c}\left(\dot{Z}_{b}-\dot{Z}_{s}\right)+K_{c}\left(Z_{b}-Z_{s}\right)-C_{s}\left(\dot{Z}_{s}-\dot{Z}_{u}\right)-K_{0}-K_{1}\left(Z_{s}-Z_{u}\right)$

$-K_{2}\left(Z_{s}-Z_{u}\right)^{2}-K_{3}\left(Z_{s}-Z_{u}\right)^{3}$

$M_{u} \ddot{Z}_{u}=C_{s}\left(\dot{Z}_{s}-\dot{Z}_{u}\right)+K_{s}\left(Z_{s}-Z_{u}\right)-K_{t}\left(Z_{u}-q\right)$.

\section{NON-LINEAR SIMULINK MODEL}

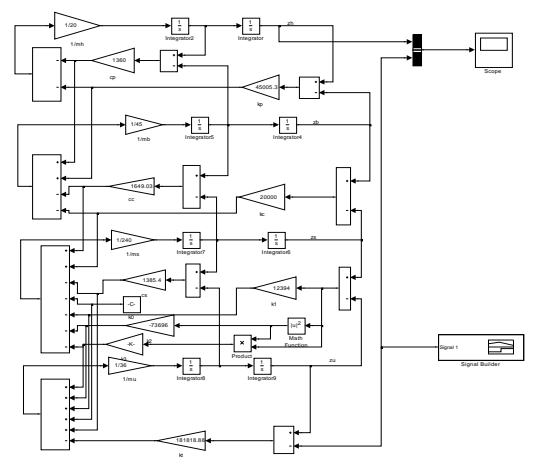

Fig.4 Non-linear SIMULINK model of quarter car model.

\section{NON-LINEAR SIMULATION ANALYSIS}

The above model is designed and simulated with consideration of non-linearity of spring in suspension system. The results are plotted with the same input parameters of road profile as that of linear simulation and the results are compared for acute relation of the effects of spring on ride comfort, road holding and head displacement.Non-linearity in damping coefficient can be neglected as it has minimal effect on head displacement. Non-linearity of spring stiffness factors to difference in the results.Fig. 5 shows displacement of head verses time domain. The head displacement were ascertained to be $0.2655 \mathrm{~m}$. Furthermore, the first crest has a maximum displacement and continues to keep on reducing to attain an equilibrium. The displacement of head tends to settle on a value greater than zero, reason being constant $K_{0}$ which does not change with time.

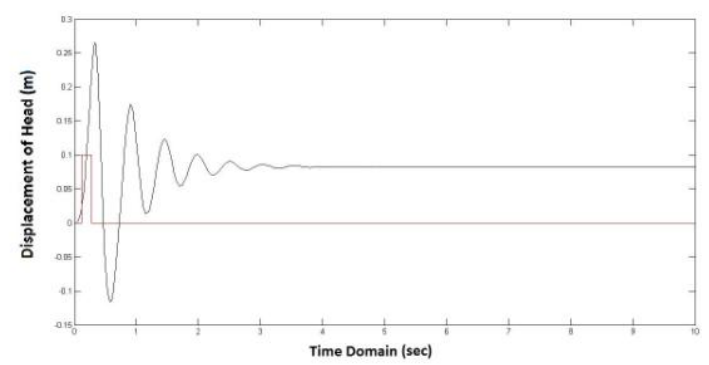

Fig.5 Non-Linear Displacement of Head Vs Time Domain 


\section{RESULTS AND DISCUSSIONS}

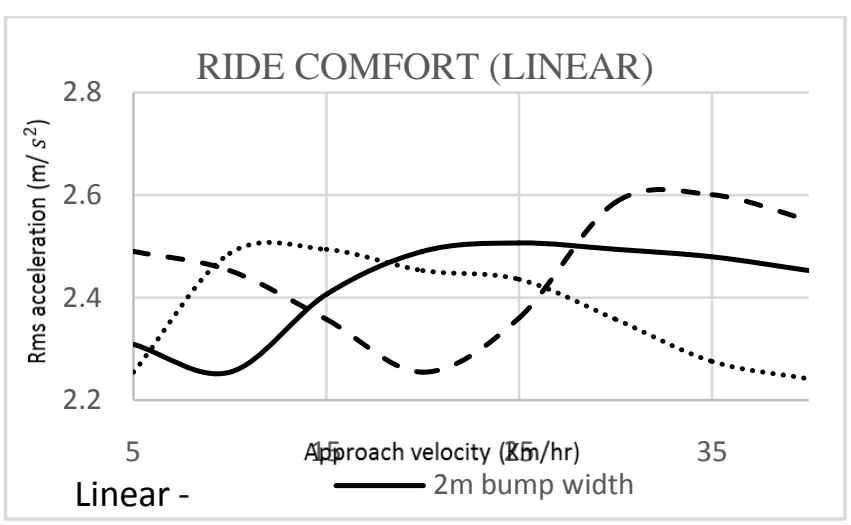

Fig.6 Ride Comfort Vs Approach velocity for linear model.

Plot in Fig.6 highlights effects of increase in approach velocity of the vehicle on the Rms acceleration, which is a criterion used for understanding the concept of ride comfort of a vehicle. The Rms acceleration determines the upward force imparted from suspension system on head on excitation of the vehicle from a bump.The increase in vehicle velocity results in increase in acceleration and decrease in ride comfort up to a certain peak limit. There is a slow declination on further increase in velocity. However, unlike $1 \mathrm{~m}$ bump width, there is a dip in acceleration for $0.5 \mathrm{~m}$ and $2 \mathrm{~m}$ bump width before attaining the gradual increase of acceleration.On the contrary, the effect of vehicle approach velocity on Rms acceleration is opposite in nonlinear model. The crosswise behaviour of the path of acceleration for $0.5 \mathrm{~m}$ and $2 \mathrm{~m}$ of increase in acceleration, and decreasing for $1 \mathrm{~m}$ width of speed bump at the start than for linear model.Plot in Fig.7, also throws light on increase in magnitude of the Rms acceleration for the same approach velocity as that of linear model. Secondly, the lower interpretations of acceleration on higher velocity as well is gradual decrease in acceleration on increase in vehicle velocity for all bump heights gives a better ride comfort experience. However, it can be concluded thateven though the suspension system absorbs the forces, yet does not have enough time for reaction. The contact between the tire and road defines the phenomenon of Road holding. Practically, road holding is very essential factor for vehicle control and breaking effect. A relative displacement between bump excitation and wheel displacement is

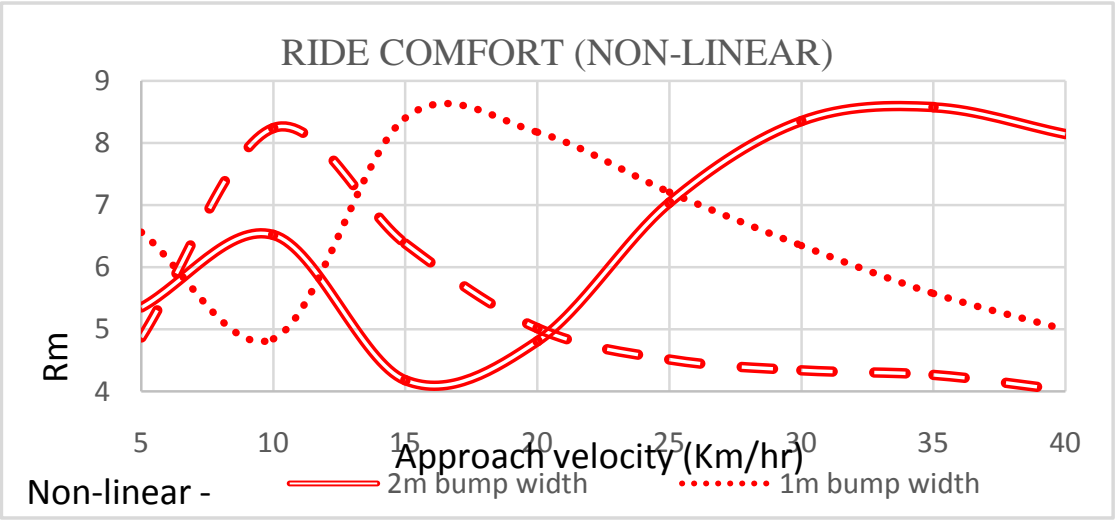
obtained.

Fig.7 Ride Comfort Vs Approach velocity for non-linear model.

The loss of contact between tire and road revolves around the concept of relative displacement being negative. Fig. 8 illustrates the significance of increase in approach velocity of the vehicle on road holding parameter for different bump widths of $2 \mathrm{~m}, 1 \mathrm{~m}$, and $0.5 \mathrm{~m}$. The relative displacement can easily be comprehended for different bump widths, as well as, linear and nonlinear models on eying of the graph. The relation of increase in displacement with increase in approach velocity is genuine, moreover the fact of increase in magnitude of displacement on decrease in bump width is apprehensive. 


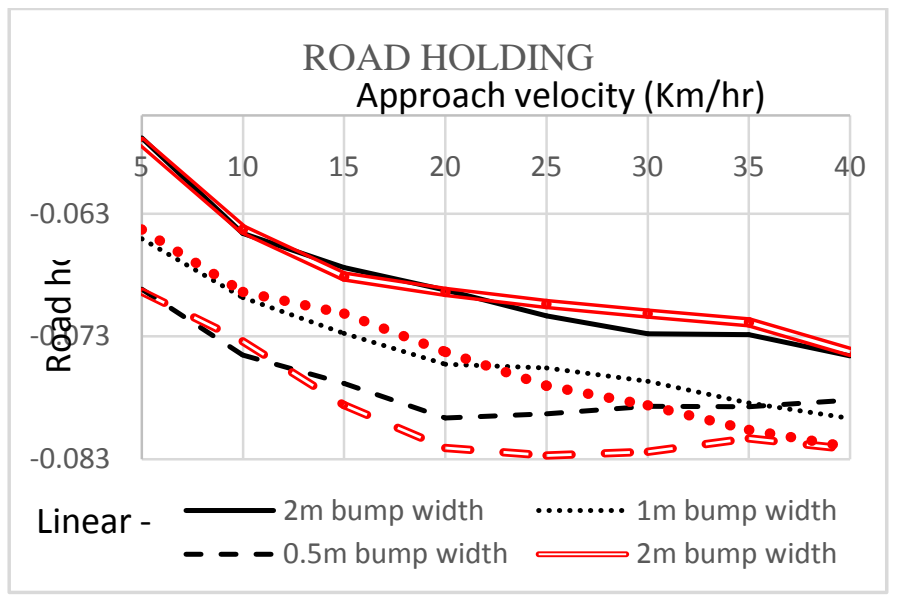

Fig.8 Road holding Vs Approach velocity for Linear and non-linear model.

Displacement of head attributes to the forces being transferred to the head through the suspension system. Figure 9 exemplifies the aftermath of approach velocity on displacement of the head from its original position.The graph interprets linear and non-linear models solely by difference in intensity, regardless of the bump width. The non-linear simulation points out a greater magnitude of displacement as compared to linear. Also, it can be generalized that displacement gradually decreases on increase in velocity, which is a consequence of lack of response time for the system.

\section{CONCLUSIONS}

The rms acceleration responsible for ride comfort and displacement of head are observed to be greater in non-linear as compared to linear model even though there is not much difference in road holding phenomenon. Moreover, optimised results are obtained for road holding, ride comfort and displacement of head on comparison of linear model to non-linear model of suspension system. Table below, illustrates results with peak values for the compared parameters. It is observed, rms acceleration responsible for ride comfort turns out to be higher in non-linear spring with $8.4 \mathrm{~m} / \mathrm{s}^{2}$ than $2.4 \mathrm{~m} / \mathrm{s}^{2}$ for linear. More optimized results are obtained for road holding and displacement of head in non-linear parameter of spring, $-0.0715 \mathrm{~m}$ and $0.097 \mathrm{~m}$ respectively.

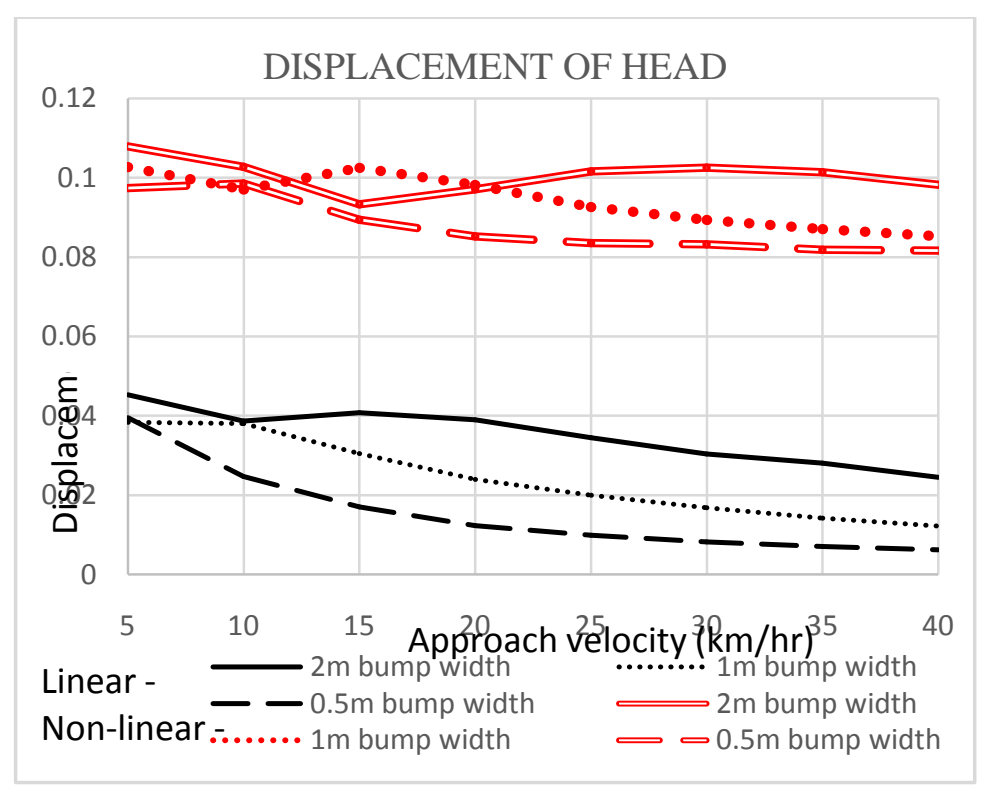

Fig.9 Displacement of Head Vs Approach velocity for Linear and non-linear model 
Table No.3: Results for linear and non-linear model simulation.

\begin{tabular}{|l|l|l|}
\hline PARAMETERS & LINEAR & NON-LINEAR \\
\hline $\begin{array}{l}\text { Max rms acceleration }(1 \mathrm{~m} \\
\text { bump width, velocity } \\
15 \mathrm{~m} / \mathrm{s})\end{array}$ & $2.494 \mathrm{~m} / \mathrm{s}^{2}$ & $8.4 \mathrm{~m} / \mathrm{s}^{2}$ \\
\hline $\begin{array}{l}\text { Road Holding }(2 \mathrm{~m} \text { bump } \\
\text { width, velocity } 35 \mathrm{~m} / \mathrm{s})\end{array}$ & $-0.073 \mathrm{~m}$ & $-0.0715 \mathrm{~m}$ \\
\hline $\begin{array}{l}\text { Displacement of Head }(1 \mathrm{~m} \\
\text { bump width, velocity } \\
10 \mathrm{~m} / \mathrm{s}\end{array}$ & $0.038 \mathrm{~m}$ & $0.097 \mathrm{~m}$ \\
\hline
\end{tabular}

\section{FUTURE SCOPE}

The field is still vast and can be mined for more accurate and optimised outcomes. Work can be laid on MSCAdams on 4-DOF suspension systems as well as concept of non-linearity of spring can be put forth in active suspension system and semi-active suspension systems.

\section{REFERENCES}

[1] A.C.Mitra, N.Benerjee,Ride comfort and Vehicle handling of Quarter Car Model Using SIMULINK and Bond Graph.,Proceedings of the 1st International and 16th National Conference on Machines and Mechanisms (iNaCoMM2013). 2013.

[2] V.K.Tewari, N. Prasad. Three-DOF modelling of tractor seat-operator system. Journal of Terramechanics 36.4 (1999): 207-219.

[3] S.H. Sawant, Dr J.A. Tamboli. Analysis and Comparison of Vehicle Dynamic System with Nonlinear Parameters Subjected to Actual Random Road Excitations. International Journal of Mechanical Engineering \& Technology (IJMET) 3.2 (2012): 284-299.

[4] RajendraKerumali, S. H. Sawant. Analysis of Nonlinearity in spring and Damper of Vibration Isolator Subjected to Harmonic Excitation, Journal of Mechanical Engineering (SSRG-IJME), 2014, ISSN: 2348 -8360 .

[5] S.S.Patole, S. H. Sawant. Theoretical and Numerical Analysis of Half Car Vehicle Dynamic Model Subjected to Different Road Profiles with Wheel Base Delay and Nonlinear Parameters. Int. J. of Multidisciplinary and Current research 3 (2015) ISSN: 2321-3124

[6] Gündoğdu, Ö9. Optimal seat and suspension design for a quarter car with driver model using genetic algorithms. International Journal of Industrial Ergonomics 37.4 (2007): 327-332.

[7] P.Chavan ,S. H.Sawant, J. A. Tamboli.Experimental Verification of Quarter Car Vehicle Dynamic SystemSubjected to Harmonic Excitation with Non-linear Suspension Parameters.IOSR Journal of Mechanical and Civil Engineering (IOSR-JMCE).ISSN: 2278-1684, 39-45.

[8] C Kim,P I Ro. A sliding mode controller for vehicle active suspension systems with nonlinearities.ProcInstnMechEngrs (212) Part D 1997. 